\title{
ON RELEVANCE.
}

A FREsh logical point is incidentally suggested by a recent discussion in Mind : namely what should be meant by 'irrelevance' in a discussion? In No. 100, page 518, I had accused Dr. Mercier of irrelevance, and he now (in No. 103, pp. 342-347) seems more concerned to rebut the charge then to inquire seriously whether perhaps there is something in it. This probably points to a difference in our conception of the nature of the fault itself. While I conceive it as, in general, an extremely common and excusable kind of mistake, he apparently conceives it as at best an easily avoided blunder. Intentional irrelevance is of course not here in question ; for that I should have no excuses to make. The examples noticed in No. 100 were all of the most innocent and natural kind, the kind which forms the substance of almost every philosophical dispute, just because in philosophy there is so little room for dispute about matters of fact.

The examples referred to are fairly typical, and we can now revise them in the further light of the defence put forward by Dr. Mercier. I objected that certain remarks of his are irrelevant to certain questions, and his answer is in effect that they are relevant to others. For no question was raised between us about the general connexion between clear thought and elegant language, nor about the disrespect due to unintelligible statements. The question was about a particular case of clumsy expression which Dr. Mercier admittedly (p. 343) does not accuse of being unintelligible. Granting then that literary or grammatical criticism is also logical criticism when it complains of a lack of meaning, what has that to do with the verbal monstrosity of the particular sentence in question ${ }^{1}$ Since its meaning is clear, the verbal criticisms are literary as contrasted with logical. But they are also irrelevant in another way. We must remember that Mr. Shelton had not a free hand in choosing the form. He had undertaken to show how an implied premiss might be forced into a

'We may notice that there was also some further irrelevance in connecting Jerons's name with this matter at all. His responsibility, Dr. Mercier uow declares (p. 347), has nothing to do with the essence of $\mathbf{M r}$. Shelton's operation-the taking of two 'propositions' as one premiss and concocting the other-but only with the form adopted for translating 'hypotheticals' into 'categoricals'. As a fact, however, Jevons was not responsible even for this. The same form was used for the same purpose, oome fifty years before, by Whately (Logic, Bk. iv, $\$ 6$ ); and the real originator of it may have been earlier still. 
certain traditional mould. He proceeds to do so, and the result is inelegant, as every one agrees and as those who know the literary defects of Formal Logic might have expected. But the inelegance, we claim, does not affect Mr. Shelton's success in his undertaking; it is due to the limits' of style to which he was ex hypothesi restricted. Dr. Mercier complains that Mr. Shelton, when not left free to choose a natural form for the implied premiss, makes use of one which is unnatural. If Dr. Mercier had undertaken to travel to Scotland in a cattle truck and had succeeded in doing so, and if I were to claim that because it was an uncomfortable mode of travelling he had failed in his undertaking, would Dr. Mercier think my objection relevant?

Again, since Mr. Shelton took a pair of so-called 'premisses' and regarded them as together forming a single premiss, it still seems to me that in order to be relevant any criticism must recognise that one of the questions he raised is whether they are really 'the premisses' or not; and that to beg this question would therefore be to ignore part of the point at issue. On the other hand Dr. Mercier has a clear right to explain that in calling them the premisses he is only following a custom he deplores; and, accepting this explanation, I see that my objection was groundless so far as he is concerned; this particular irrelevance, I willingly agree, is not to be laid to his charge. My objection itself was therefore irrelevant.

As regards the other two charges of irrelevance, Dr. Mercier seems to have somehow overlooked my explanation of them (No. 100 , p. 519)-that, on account of certain specified ambiguities in the questions raised, no direct answer that can be given to them would be relevant to the difficulties they profess to deal with. These ambiguities are, I think, important, and I hope that in any future remarks Dr. Mercier cares to make on this subject he will either show their unimportance or take them into account. 1 What I meant was that, as against those opponents who see the ambiguity of the questions-and who hold that the use of a universal in reasoning is only required where (1) the argument is not merely verbal, and (2) the need of proof is felt-it is irrelevant to show that no universal is made use of in (1) merely verbal substitutions or (2) conclusions reached uncritically or assumed to be selt-evident. In the case of the simple a fortiori argument from which the discussion started it is true that in daily life we never dream of doubting the conclusion, but the question as it arose was not about this sensible and careless procedure, but about the pro-

1 A fresh example of his ignoring them occurs on page 340 , where ho misquotes me as actually usiing onte of the ambiguous phrases-" we obtain this cunclusion through" a universal. If he would re-read the passage (No. 100, pp. $530-521$ ) he would see that I not only did nut use this phrase, but explained my avoiclance of it. And Mr. Sholton's comments, at page $3 \overline{8}$, show that my menning was clear at least to him, though he thinks the linitation unnecessary. 
cedure of any careful logic if we should happen to want to use it. What gives some value to this 'if' is the difficulty of drawing any clear line between conclusions which can and which cannot be usefully doubted. That may be some excuse for Euclid's thinking it worth while to set out his obvious and tiresome principles in verbal form. ${ }^{1}$

Dr. Mercier's remarks in No. 103 contain at least two fresh irrelevances. First, it is evident (p. 344) that he and I mean something different by a 'syllogism'. The definition I give to the word, as indicated in No. 100 , at the top of page 520 , is "the application of a general rule to a particular case". Now Dr. Mercier cannot mean that this process is "powerless to cope with facts asserted as true" or that it is " a small and insignificant part of the machinery of inference". What he apparently does mean-and what no one would dispute-is that when the application of a rule to a case is used as a mere supposition, then it is not concerned with facts asserted as true; and that this tentative use of it is only a small part of inference as a whole. If this is what he means, how does he suppose that his view conflicts with mine, and what is then the relevance of his protest? A question might be raised about the value of his proposed restriction of the meaning of the word 'syllogism,' and we might disagree about that. It seems to me better to recognise three different uses of a 'syllogism '-three different ways in which rules may be applied to cases: (1) where we assert a conclusion and support it either by asserting both the premisses or (more commonly) by asserting one and implying the other; (2) where we do not assert either the conclusion or the premisses, but merely speculate on the conclusion 'which, if true, the premisses would support; this, I suppose, is 'the syllogism ' in Dr. Mercier's sense ; and (3) where we accept (whether rightly or not) a rule and an application of it, and draw from these premisses a conclusion we had not thought of before. This last is the rarest and least important use of the syllogism, and no doubt Dr. Mercier agrees with me that it bulks too large in the traditional logic.

There seems to be a difference also between our views of the nature of reasoning from facts. Dr. Mercier's conception of this process would perhaps gain by his giving more importance to the method of analysis. Is it not true that, except in early stages of an inquiry, we always try to look behind the mere number and constancy of our experiences of the C-ness of B? TVe break up the crude facts into details to which we can give some meaning through our previous beliefs about special causes and effects. Each detail so regarded is the (supposed) application of a (rightly or wrongly) trusted rule. Criticism of the process, step by step, con-

\footnotetext{
1 At page $347 \mathrm{Dr}$. Mercier seems to throw doubt upon the intended universality of the theorem proved in Euclid, Bk. i, Prop. 20, on the ground that ' $a$ ' triangle, not 'any' triangle is spoken of. Then how does he account for the consequences drawn from it in Euclid's next Proposition ? 'This use of ' $a$ ' for 'any' is a common English practice, and the objection. seems to me excessively formal.
} 
sists in raising the questions (1) whether a given rule of causation is rightly trusted, and (2) whether a supposed application of it properly deserves to be called so. The chief use of this "syllogistic" view of reasoning from facts is that it filters out for us these two separate questions; and the chief danger of it is that in separating them we are liable to overlook their necessary interdependence, and so to be content with an ambiguous middle.

Secondly, it is irrelevant to describe as a "plain issue" (p. 346) an issue which has already been found ambiguous. By calling it ambiguous I meant that Dr. Mercier's question, as he states it, admits of the meaningless double answer "yes and no," and that these answers can only be reduced to one by removing the ambiguity. In No. 100, page 519, my difficulties were stated, and there is therefore no need to repeat them here. As, however, Dr. Mercier now says that he has no objection to the use of a universal if it is wanted, all that remains is to repeat my question whether concocting a universal from a given minor premiss and conclusion is a process that is ever wanted; and if so for what purposes? The meaning of this question may be clearer now that some of the differences in our views of the syllogism have appeared. It seems to me that in reasoning from a fact to a conclusion the attempt to regard that fact (or some detail in it) as coming under a rule necessitates an attempt to state the rule so that its meaning shall be clear. The use of this attempt is that it is only in the form of a statement that the truth of the rule can be carefully criticised. A vaguely apprehended rule may deceive us, and in making it definite we are more likely to discover its faults. I have already (No. 100, p. 521) agreed that the rule implied in the a fortiori argument is an extreme case of a rule the expression of which is in daily life unlikely to be wanted. But in view of the difficulty of saying in general which rules on what occasions would gain the requisite definiteness by expression it seems to me better that logic should make provision even for extreme cases, and that we should then, in everyday practice, use our discretion as to calling in logic's aid. Thus I quite agree that to set out the implied major premiss of the a fortiori argument is an operation that no one would think worth while except when required to do so in the name of logical theory.

The examples here noticed of irrelevant arguing may help to show how many opportunities for it occur innocently in disputes about logical points. Sometimes irrelevance takes the form of proving against an opponent what the opponent freely admits; sometimes of ignoring a distinction on which his argument openly turns; sometimes of forgetting the conditions by which he bas chosen to limit himself ; sometimes of begging part of the question raised; or again of accusing him of begging a question when he has not done so; sometimes of ignoring an ambiguity which he has asked to have removed; sometines of ignoring a definition-i.e., a postulate about the meaning of a word. And what is common to all these (and other) varieties is that a meaning has been misin- 
terpreted. Now a given misinterpretation may be anybody's fault -or nobody's. There is often no blame to be laid upon the person who commits it; and no blame was laid by me upon Dr. Mercier. No more blame need attach to irrelevance than to our failure to catch a remark in a noisy street. Misinterpretation of a statement, or an argument, is often only a natural result of excusable pre-occupation with some other point of view. Indeed there would almost be something uncanny about a philosopher who never did mistake his opponents' meaning.

Alfred Sidgwick. 